\title{
PEDIATRIC
}

\section{VACTERL association - Ultrasound findings and autopsy correlation}

\section{Naman Kumar Gaur, Sudheer Gokhale}

Department of Radiodiagnosis, Sri Aurobindo Institute of Medical Sciences and Post Graduate Institute, Indore, Madhya Pradesh, India

Correspondence: Dr. Naman Kumar Gaur, 302 Kamlasan Aptt. Navlakha, Indore, Madhya Pradesh, India. E-mail: gaur.naman@gmail.com

\begin{abstract}
VACTERL (vertebral, anal, cardiac, tracheoesophagus, renal, and limbs) is an abbreviation for the congenital group of abnormalities, including vertebral or vascular anomalies, anal atresia, cardiac defects, tracheoesophageal - fistula/esophageal atresia, renal defects, and limbs defects. It is a rare association and not accidental event where several organs are affected by developmental defects during blastogenesis. The exact cause is unknown; however, several environmental and genetic factors are included in literature. Three components out of seven are used to label as VACTERL. The combination is necessary, but the patient may have other congenital malformations as well. We present here an antenatal scan with autopsy correlation of one of the forms of VACTERL association spectrum.
\end{abstract}

Key words: Diagnosis of exclusion; VATER; vertebral, anal, cardiac, tracheoesophagus, renal, and limbs

\section{Introduction}

VACTERL association is a constellation of vertebral $(\mathrm{V})$, anal (A), cardiac (C), tracheoesophageal (TE), renal (R), and $\operatorname{limb}(\mathrm{L})$ anomalies in a single individual with an incidence of $1 / 10,000-1 / 40,000$, approximately $1-9 / 100,000 .^{[1]}$

Quan and Smith were the first to describe VATER association in 1973 which did not include cardiac and limb anomalies. ${ }^{[2]}$ Later, Temtamy et al. suggested the inclusion of VSD and single umbilical artery in the V of VATER association. ${ }^{[3]}$ Recently, VACTERL-H has been described by Zen et al. for associated hydrocephalus $(\mathrm{H})$ in the newborn. ${ }^{[4]}$

The etiology of VACTERL is unknown and many cases occur sporadically. Several authors have suggested developmental defects during blastogenesis (2-4 weeks of gestation) which impair the formation of multiple organs

\begin{tabular}{|l|l|}
\hline \multicolumn{2}{|c|}{ Access this article online } \\
\hline Quick Response Code: & \\
\cline { 1 - 2 } & Website: \\
\hline & www.ijri.org \\
\cline { 2 - 3 } & DOI: \\
\hline
\end{tabular}

simultaneously ${ }^{[5]}$ Environmental factors such as maternal diabetes mellitus, alcohol, and teratogenic drugs are the most common causes. In addition to these prime features, patients may also have other congenital anomalies such as hydrocephalus, ribs, and branchial arch anomalies.

\section{Uniqueness of This Case}

Gradual narrowing of abdominal aorta and a globular structure in place of urinary bladder communicating with small bowel are a very rare occurance with typical VACTERL features. Low set ears are difficult to imaging on ultrasound.

\section{Case History}

A young lady, para 2 and gravid 3 was referred to our department for targeted/anomaly/level II scan, with no

This is an open access journal, and articles are distributed under the terms of the Creative Commons Attribution-NonCommercial-ShareAlike 4.0 License, which allows others to remix, tweak, and build upon the work non-commercially, as long as appropriate credit is given and the new creations are licensed under the identical terms.

For reprints contact: reprints@medknow.com

Cite this article as: Gaur NK, Gokhale S. VACTERL association - Ultrasound findings and autopsy correlation. Indian J Radiol Imaging 2018;28:452-5. 
previous significant history. Her gestational age according to her last menstrual period was 20 weeks 5 days.

\section{Ultrasound Findings}

Placenta was high posterior in position. Measured fetal parameters of biparietal diameter such as head circumference, humerus, ulna, and radius showed foetus corresponding to 18-19 weeks.

Endocardial cushion defect (absent crux) was seen along with right tricuspid regurgitation [Figure 1]. Stomach was appreciated normally [Figure 2]. Couple of small cystic structures were seen in place of left kidney [Figure 3]. There was only single umbilical artery visible with absent bladder [Figure 2]. Right umbilical artery was seen originating from abdominal aorta and showed tortuous course [Figure 4]. Lumbo-sacral (LS) region showed hemi-vertebra [Figure 5]. Abdominal aorta was thin in caliber [Figure 4]. On detailed examination, only left leg was visualized.

The patient then opted for termination at 19 weeks. On autopsy, low set ears were observed [Figure 6]. Tracheoesophageal fistula could not be ruled out. Hemi-vertebra was noted in lower LS spine [Figure 7]. Right kidney was absent. Left kidney was cystic in nature and ureter was attached to it noted [Figure 7]. The umbilical cord showed one artery and a vein. Bladder was

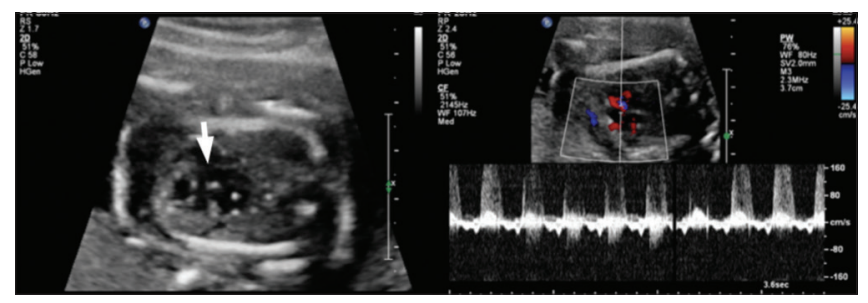

Figure 1: (Left) Endocardial cushion defect in form of absent crux. (arrow). (Right) Tricuspid regurgitation noted

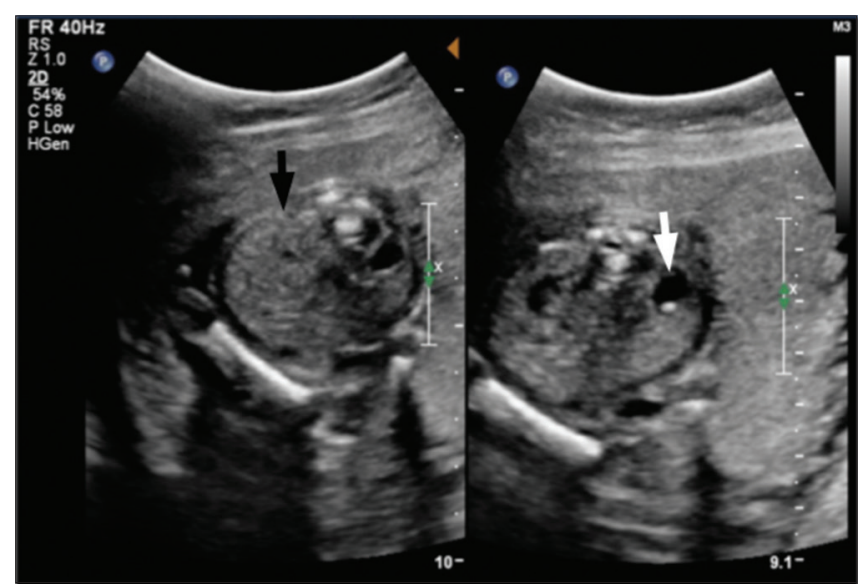

Figure 3: A cystic structure seen in place of left kidney (arrow) and right kidney not appreciated well (black arrow) absent; instead, a globular firm structure was present in its place (part of colon) [Figure 8]. Central nervous system was unremarkable. Genitalia was confirmed as male with urethral opening noted in center [Figure 7]. Anal atresia was also appreciated [Figure 7]. Abnormal course of right umbilical artery [Figure 8] was noted and right leg was absent [Figure 6].

\section{Discussion}

Of all the associations, vertebral anomalies occur in $60 \%-80 \%$ of cases. ${ }^{[6]}$ Renal anomalies occur in $50 \%-80 \%$ of the cases in the form of unilateral renal agenesis, horseshoe, and cystic and/or dysplastic kidneys as our case showed no right kidney with cystic left, respectively. Genitourinary defects include ambiguous genitalia, genitourinary fistula, cryptorchidism, and hypospadias. Statistical analyses of cohorts of affected patients done by Kallen et al. suggested that there was overall less evidence for the inclusion of certain features, such as cardiac or renal anomalies. ${ }^{[7]}$

Cardiac anomalies occur in $50 \%-80 \%$ of cases as VSD, ASD, and tetrology of Fallot, being frequently reported defects. ${ }^{[8]}$ Tracheoesophageal anomalies comprises $50 \%-70 \%$ of patients and they may be associated with lung anomalies. Limb anomalies occur in $40 \%-55 \%$ of patients and include radial ray deformities, club foot, hypoplasia of great toe/tibia and lower limb, and tibial deformities. ${ }^{[9]}$

Due to its wide variety of associations and no specific genetic defect, it becomes a diagnosis of exclusion and also results in comprehensive list of differentials. While many syndromes overlap with VACTERL, some demand special mention such as Alagille syndrome (typical facial
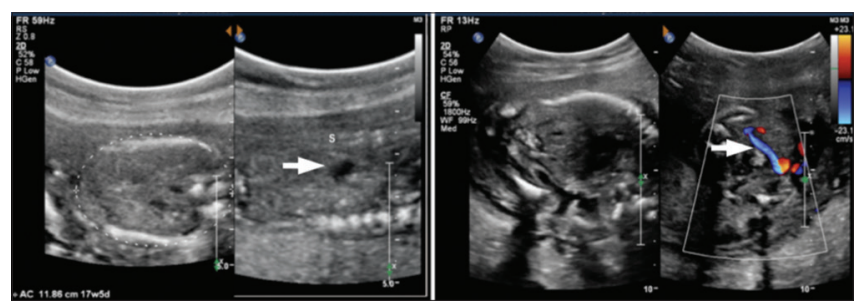

Figure 2: (Left) Stomach was normally appreciated (arrow). (Right) Single umbilical artery appreciated with absent urinary bladder (arrow)

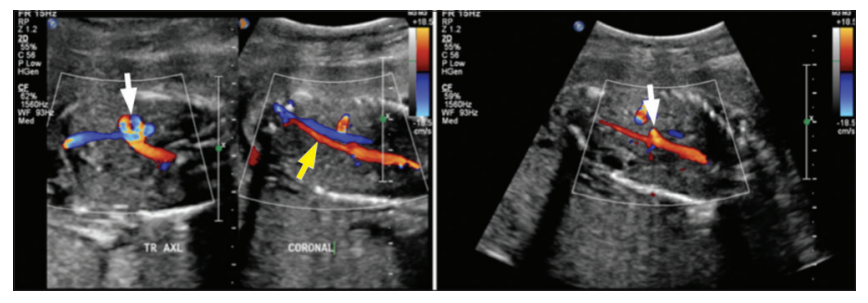

Figure 4: (Left) Abnormal tortuous course of right umbilical artery noted (arrow) and thinned out abdominal aorta (yellow arrow). (Right) Right umbilical artery originating from abdominal aorta (arrow) 


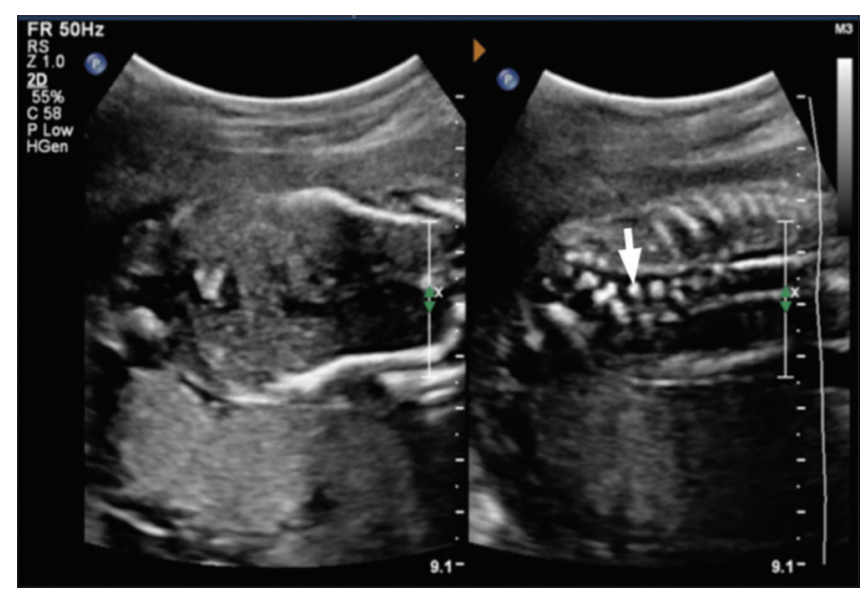

Figure 5: Hemi-vertebra noted in lumbo-sacral region of spine (arrow)

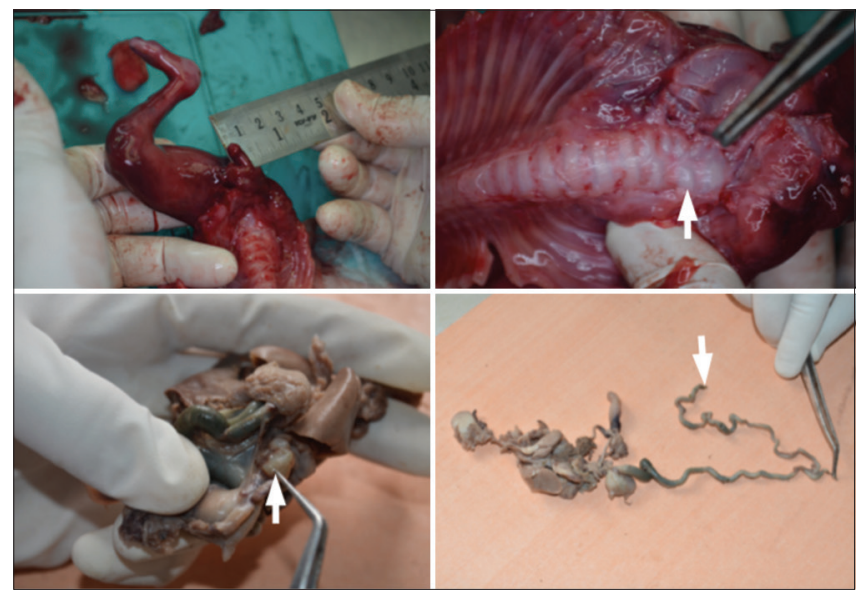

Figure 7: (Left upper) Fetus had male genitalia. (Right upper) Hemi-vertebra confirmed as seen in ultrasound (arrow). (Left lower) Cystic structure in place of left kidney. Right kidney was not appreciated (arrow). (Right lower) A blind ended terminal bowel was noted representing anal atresia (arrow)

appearance or ophthalmic anomalies), Baller-Gerold syndrome, CHARGE syndrome, Fanconi's anemia, Feingold's syndrome, Fryns' syndrome, and Holt-Oram syndrome. ${ }^{[10]}$

It is important to note that the discovery of a single umbilical artery may be the first indication of the diagnosis. ${ }^{[11]}$ Heterozygous mutations in HOXD13 are typically reported as resulting in limb and/or urogenital anomalies. ${ }^{[12]}$ Heterozygous/hemizygous mutations in ZIC3 include obvious heterotaxy/situs abnormalities. ${ }^{[13]}$ Mitochondrial dysfunction ${ }^{[14]}$ have been reported as nonspecific genetic defects.

They have small risk of having several affected people in a family. The risk of relapse is likely to be relatively low as long as similar conditions with hereditary forms (such as Fanconi's anaemia, Feingold syndrome, Holt-Oram syndrome, Townes-Brock syndrome, and VACTERL with hydrocephalus) are excluded. ${ }^{[15]}$

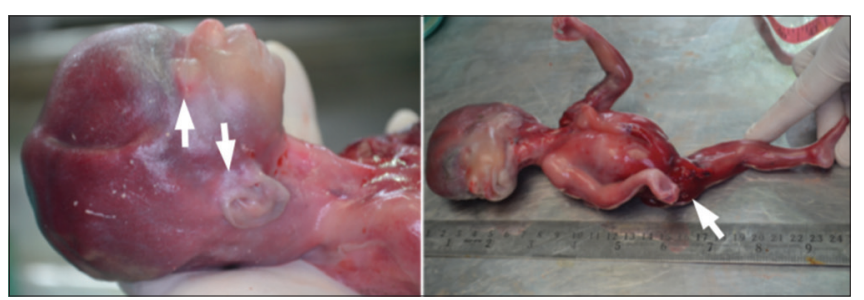

Figure 6: (Left). Low set ear compared with canthus. (arrows). (Right) Completely absent right lower limb

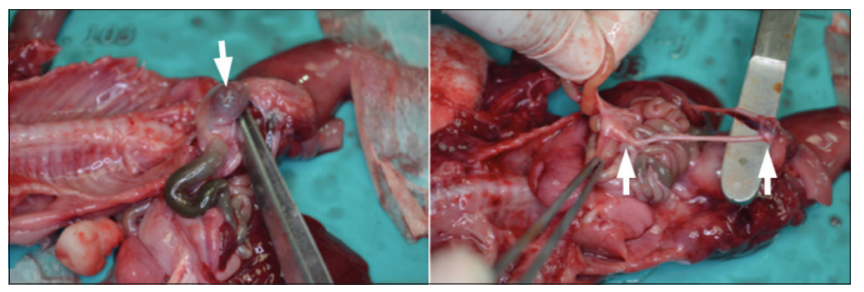

Figure 8: (Left) In place of urinary bladder, a firm nodular lesion was noted which was communicating with bowel (arrow). (Right) Origin of right umbilical artery from abdominal aorta and its tortuous and abnormal course as seen in ultrasound (arrows)

Low set ears were discrete findings in our case, as also shown by Weaver DD et al. ${ }^{[16]}$ and Mc Cauley J et al. ${ }^{[17]}$ in their studies and kept them in minor characteristic of VACTERL. Absent urinary bladder found in our case was considered extreme variety of VACTERL by Dusmet $\mathrm{M}$ et al. ${ }^{[18]}$

\section{Conclusion}

- VACTERL association is sporadic, variable in presentation, and a rare incidence

- Although karyotyping has not showed any promise, diagnosing by exclusion remains a mainstay with knowledge of associating conditions

- Antenatal life sustain issues are to be kept in mind with postnatal rehabilitation and surgical correction shows promise.

Acknowledgement

The authors acknowledge radiodiagnosis department, SAMC and - PGI, Indore.

\section{Declaration of patient consent}

The authors certify that they have obtained all appropriate patient consent forms. In the form the patient(s) has/have given his/her/their consent for his/her/their images and other clinical information to be reported in the journal. The patients understand that their names and initials will not be published and due efforts will be made to conceal their identity, but anonymity cannot be guaranteed.

Financial support and sponsorship

Nil.

Conflicts of interest

There are no conflicts of interest. 


\section{References}

1. Botto LD, Khoury MJ, Mastroiacovo P, Castilla EE, Moore CA, Skjaerven $\mathrm{R}$, et al. The spectrum of congenital anomalies of the VATER association: An international study. Am J Med Genet 1997;71:8-15.

2. Quan L, Smith DW. The VATER association. Vertebral defects, Anal atresia, T-E fistula with esophageal atresia, Radial and Renal dysplasia: A spectrum of associated defects. J Pediatr 1973;82:104-7.

3. Temtamy SA, Miller JD. Extending the scope of the VATER association: Definition of the VATER syndrome. J Pediatr 1974;85:345-9.

4. Chen Y, Liu Z, Chen J, Zuo Y, Liu S, Chen W, et al. The genetic landscape and clinical implications of vertebral anomalies in VACTERL association. J Med Genet 2016;53:431-7.

5. Cevik MO, Celik M, Bucak IH, Almis BH, Turgut M. Possible relation of antenatal venlafaxine Use and VACTERL association in a Newborn: A case report. Turkish J Psychiatr 2017;28.

6. Vertebral defect, anal atresia, cardiac defect, tracheoesophageal fistula/esophageal atresia, renal defect, and limb defect association with Mayer Rokitansky-Küster-Hauser syndrome in cooccurrence: Two case reports and a review of the literature. J Med Case Rep 2016;10:374.

7. Källén K, Mastroiacovo P, Castilla EE, Robert E, Källén B. VATER non-random association of congenital malformations: Study based on data from four malformation registers. Am J Med Genet 2001;101:26-32.

8. Ramosa JA, Shashank S. Shettarb SS, James CF. Neuraxial analgesia in a parturient with the VACTERL association undergoing labor and vaginal delivery. Rev Bras Anestesiol 2016;343-9.

9. Reddy AKV, Soren C. VACTERL association in a newborn - A rare case report. IOSR J Dental Med Sci 2017;16:31-3.

10. De Falco F, Cainarca S, Andolfi G, Ferrentino R, Berti C, Rodríguez Criado G, et al. X-linked Opitz syndrome: Novel mutations in the MID1 gene and redefinition of the clinical spectrum. Am J Med Genet 2003;120A: 222-8.

11. Murphy-Kaulbeck L, Dodds L, Joseph KS, Van den Hof M. Single umbilical artery risk factors and pregnancy outcomes. Obstet Gynecol. 2010;116:843-50.

12. Zhao X, Sun M, Zhao J, Leyva JA, Zhu H, Yang W, et al. Mutations in HOXD13 underlie syndactyly type $\mathrm{V}$ and a novel brachydactyly-syndactyly syndrome. Am J Hum Genet 2007;80:361-71.

13. Gebbia M, Ferrero GB, Pilia G, Bassi MT, Aylsworth A, Penman-Splitt $\mathrm{M}$, et al. X-linked situs abnormalities result from mutations in ZIC3. Nat Genet 1997;17:305-8.

14. Solomon BD, Patel A, Cheung SW, Pineda-Alvarez DE. VACTERL association and mitochondrial dysfunction. Birth Defects Res A Clin Mol Teratol. (In press).

15. Kohlhase J, Wischermann A, Reichenbach H, Froster U, Engel W. Mutations in the SALL1 putative transcription factor gene cause Townes-Brocks syndrome. Nat Genet 1998;18:81-3.

16. Weaver DD, Mapstone CL, Yu PL. The VATER association: Analysis of 46 patients. Am J Dis of Child 1986;140:225-9.

17. McCauley J, Masand N, McGowan R, Rajagopalan S, Hunter A, Michaud JL, et al. X-linked VACTERL with hydrocephalus syndrome: Further delineation of the phenotype caused by FANCB mutations. Am J Med Genet Part A 2011; 155:2370-80

18. Dusmet M, Fete F, Crusi A, Cox JN. VATER association: Report of a case with three unreported malformations. J Med Genet 1988;25:57-60. 